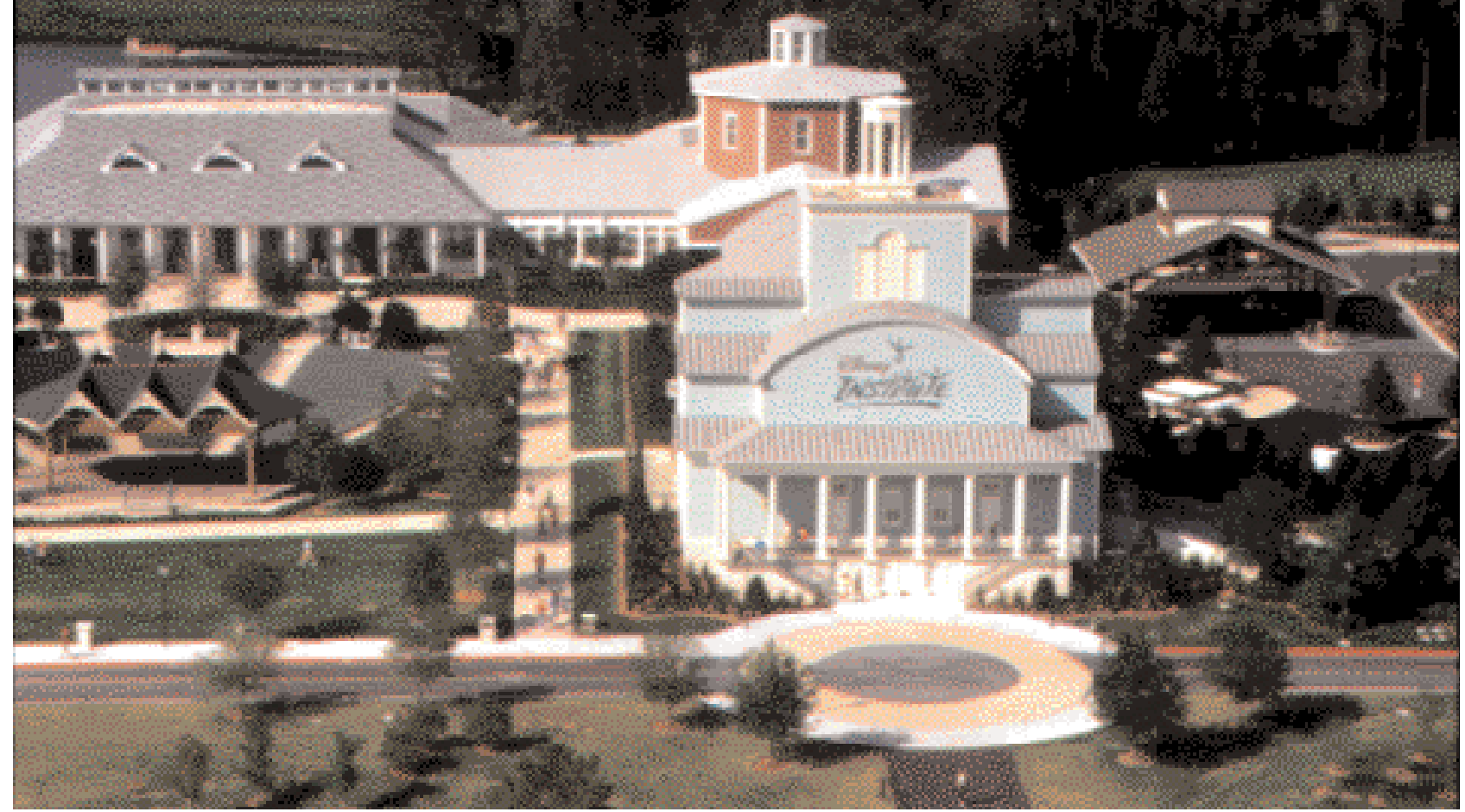

\title{
Tapping Disney Inspiration: Transforming Healthcare
}

\section{CRaig TAYLOR}

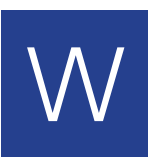

hen you think of the Walt Disney World $®$ Resort, you think of rides, shows, food, and fun. You probably don't think of professional development. And you certainly don't think of healthcare training. But in the heart of Walt Disney World Resort, has been created an experience for healthcare professionals that is unlike any other. More than 3,000 healthcare professionals have travelled to Disney Institute in recent years to study the leadership, management and service strategies of the Walt Disney World Resort. In fact, healthcare professionals make up a solid 30\% of our Disney Institute professional enrollment.

\section{Why Disney and Healthcare?}

At first we weren't sure why so many of our participants were from healthcare. But a closer study revealed many practical and important connections between what we do at Disney and what the healthcare industry needs today.

To begin, healthcare organizations are very interested in learning how they can capture the same success enjoyed by the world's number-one vacation destination. It's our reputation for high-quality entertainment and first-class service that attracts vacationers. People cherish the special moments they experience here - that's what they take home and that's what brings them back.

You may wonder how those memorable experiences are created. Well, that's the primary focus of the Disney Institute professional programs. Business professionals want to know how Disney manages to create success year after year and at Disney Institute, we're willing to share that knowledge. In a nutshell, we tell our participants how we do it. Whether we're talking about customer loyalty, leadership or people management, we make it clear that we've had struggles in our history and we share how we've overcome them.

But that's not all. What sets us apart is that we take it a step further. We take them backstage and let them see a part of Disney that most people never see - where the magic is made, how it's made, and how that relates to what they do in their own industry.

With competition and complexity increasing in the healthcare industry, it's worth noting that we face many of the same challenges as healthcare providers. We have 22,000 beds on our property. Daily, we take thousands of guests through the check-in/check-out process. Each will stay with us for an average of three to four nights. And they expect their rooms to be clean. What hospital can't relate to that?

We also deal with similar customer issues. For example, we're constantly addressing the issue of long wait times for attractions, especially during the summer months. That happens to be a prominent issue in healthcare facilities as well. Additionally, people spend a lot of money here. We have to make sure we're providing an excellent value for the cost. The healthcare industry also faces enormous challenges in this area. 
But the biggest connection is the excellent example of customer service that Disney provides. Our healthcare clients know something is missing from their organizations. In a word, it's service. All the state-of-the-art medical equipment in the world can't replace good service. Disney knows how to treat people the way they want to be treated. That's what most of our participants come here to learn.

\section{The Quality Service Approach}

At Walt Disney World, we call our customers "guests," and we take great care to learn what those guests need, want, think and feel while they are at Disney. To provide all guests with "clean, friendly fun" during their stay, we focus on removing all obstacles to enjoyment and anticipating all guest needs. Systems and processes are built in to daily operations such that exceptional guest service is not so exceptional - it's business as usual.

"Everything Speaks" is the philosophy taught in "The Disney Approach to Quality Service for Healthcare Professionals." Participants are introduced to the concept of "guestology," an idea that encompasses every possible element of the guest experience. It starts the moment a guest calls to make reservations and continues until the guest returns home. Everything matters and no concern is too small, because the impression that guests leave with will include everything they see, hear, feel, smell, perceive, imagine, and think during their stay. From landscaping to signage to cleanliness, each aspect of the experience is considered an opportunity to improve customer service and create more magic.

Participants in "Quality Service" are asked to think about the service they offer in their own operation. What happens when a patient calls the hospital for test results? Are they transferred to various departments? Are the phone agents knowledgeable and empathetic to patient needs? And what about when they enter the facility? Is the lobby clean and attractive? Are the plants alive? The answers to these kinds of questions are crucial for ensuring that customers are having the ideal experience while inside a healthcare facility.

Another key element in the Disney guest service experience is the crucial point of interaction with Disney employees - or "Cast Members" as we call them. Ask any Disney guest and they'll report that the Cast Members are smiling and making eye contact. They're eager to answer questions, and they're knowledgeable about the entire Disney operation.

What's the secret? In "The Disney Approach to People Management for Healthcare Professionals," participants board the bus to go backstage to meet with these Cast Members to find out. They learn that Walt Disney World is willing to invest time and money in earning the dedication of employees. Investing in the happiness of employees means providing them with the motivation to create wonderful experiences for guests.
In the end, it is the Cast Members who go out and create the Disney "magic."

And in the end, it is the employees who make or break the success of a healthcare institution, Disney Institute participants begin to realize. Job satisfaction often translates directly to how employees treat patients and families. And the best part is that this kind of satisfaction is relatively easy to achieve. Often employees want a few simple things, such a private dining area, or better access to supplies, or recognition for their achievements.

\section{Adopting and Adapting "Magic"}

Perhaps the best example of how Disney concepts translate into healthcare is found at a suburban New Orleans hospital. Since 1989, East Jefferson General Hospital has been focusing on customer service. It began when CEO Peter Betts first made the trip to Disney to study the service and people management strategies of our entertainment organization and explore how those strategies could produce a better healthcare operation. East Jefferson has been learning and adapting the Disney methods ever since.

Using the Disney example, Betts and the staff of East Jefferson set out to create a simple mission statement, one that each employee (now called "team members") could commit to memory. As Disney Institute facilitators tell participants, having a clear mission aligns everything under one objective — whether you're building a new park or deciding where to put the trash cans.

The East Jefferson team decided that their primary goal was to provide "care and comfort." Those words became the focus of every subsequent decision. Contained within that goal were the values of providing service, demonstrating "courtesy and respect" and creating a "satisfying experience" for each patient and family member.

With funding on hand for new construction, Betts and his team made a concerted effort to adapt another important Disney practice - the practice of separating "on-stage" and "off-stage" from the customer perspective. As Betts says, "This concept is very important. After all, no one wants to get into an elevator and have the trash cart rolled in with them." The hospital's new 128,000 square-foot outpatient pavilion was designed specifically with the on-stage/off-stage concept in mind.

East Jefferson quickly adopted what they termed "Our House." Disney guests never see the hustle and bustle that goes on behind the scenes because it would disrupt the guest experience. Likewise, "Our House" meant resolving to keep public areas clean, free of equipment and debris, and operating with ease. "Off-stage" at East Jefferson became the area where Team Members could relax or conduct the not-so-attractive business that produces the quality service experience "on-stage." 
As with Disney, each new person hired to work at East Jefferson goes through a rigorous screening process. They are introduced to the "care and comfort" value, the dress code expectations and the commitment to outstanding service for customers. Only one in 10 job candidates who go through the screening process each year is actually hired to work at East Jefferson.

We consider East Jefferson to be our model organization for successfully adapting Disney strategies to healthcare. And the feeling is mutual. As Betts recently told us, "I am very pleased with what we learned from our Disney experience. It has helped to enhance our customer service culture more than any other external event or experience. We continue to draw upon my original experience and others that we have had since my visit in 1989 that started it all."

\section{The Magic Spreads}

Word of East Jefferson's success spread quickly. In the years following the transformation, other healthcare organizations began looking to Disney Institute for examples of service excellence and people management. As they benchmarked with the Walt Disney World Resort, they found ways to adapt the principles and practices to healthcare.

In keeping with the Disney quality service example, many healthcare facilities have established new customer service standards. One Missouri hospital set out to understand its own "guestology" by holding in-depth focus groups with patients and families, as well as community and business leaders. The result: an increased focus on staff sensitivity and courtesy, privacy for patients and better explanations to patients about the care they are receiving.

Another Virginia facility found that investing in television and VCRs for every room significantly reduced frustrations on the part of employees and patients. They also found that even simple items - such as extra pillows and blankets, juice, and ice - produced far greater levels of satisfaction with the overall healthcare experience.

Still other facilities have embarked upon transforming the entire culture of their organizations to be customer-service focused. A New Jersey medical centre keeps a Patient Satisfaction Scrapbook and encourages regular employee contributions. Staff members are asked to share patient satisfaction stories in meetings. The company newsletter is focused on personal triumphs with patients, rather than policies and procedures.

\section{A Different Kind of Learning}

The Disney Institute experience is not a typical by any means. In fact, when you come right down to it, we don't teach anything here. Simply put, we show our participants how Disney approaches these critical business issues. They take those examples and adapt them to their own organizations.

The classroom adventure at Disney Institute is both unique and invaluable. Our instructional style is experiential. Our programs feature interactive discussions, group activities, and most importantly, field excursions to behind-the-scenes areas where classroom concepts are demonstrated in a realistic settings. We feel we can teach more in a one-hour, real-life field experience than in an eight-hour lecture.

As the healthcare industry continues to encounter sensitive and complex issues, professionals will continue to search for ways to make the healthcare experience more effective for patients and families. At Disney Institute, we're committed to providing excellent examples and learning experiences that can inspire transformation in healthcare. $\mathbf{Q}$

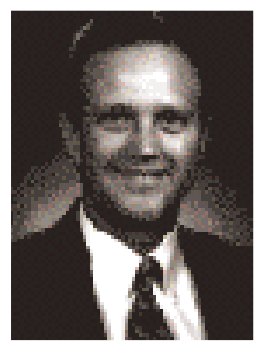

Craig Taylor is Director of Business Programs at the Disney Institute.

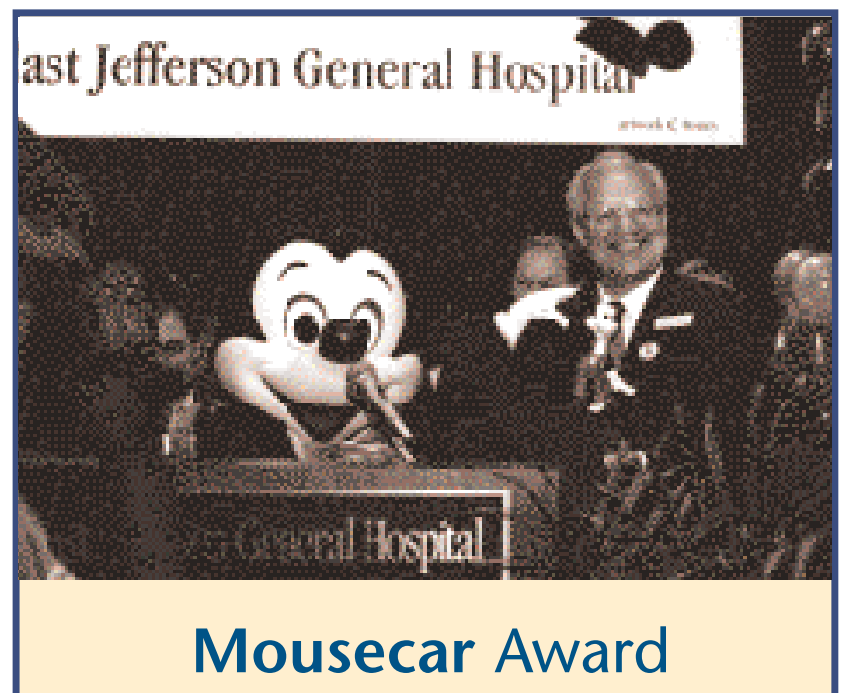

East Jefferson General Hospital was awarded a "Mousecar" (a takeoff on the Oscar) in a ceremony in February 1997. Mickey Mouse was in person to present the award. The Louisiana Hospital was recognized by Disney for its outstanding achievement in customer service. 